\title{
Kalp Yetersizliği Hastalarında Uyku Sorunları ve Nonfarmakolojik Tedavi Yöntemleri
}

\author{
(1) Abdullah Avcı, ${ }^{1}$ 이 Meral Gün² \\ ${ }^{1}$ Mersin Üniversitesi Hastanesi, Kardiyoloji Kliniği, Mersin \\ ${ }^{2}$ Mersin Üniversitesi Hemşirelik Fakültesi, İç Hastalıkları Hemşireliği Anabilim Dalı, Mersin
}

\begin{abstract}
Özet
Temel ve vazgeçilmez bir gereksinim olan uyku kalp yetersizliği hastalarında yaşam kalitesi ve iyilik durumunu etkileyen en önemli faktördür. Kalp yetersizliğinde görülen nefes darlığı, öksürük, yorgunluk, noktüri, depresyon gibi semptomlar uyku kalitesinin bozulmasına, uyku kalitesinin bozulması ise hem hastalığın semptomlarının artışına hem de yaşam kalitesinin azalmasına neden olmaktadır. Kalp yetersizliği hastaları uykuyu başlatma ve sürdürmede zorluk, gece sık uyanma, gündüz aşırı uykuluk hali ve sabahın erken saatlerinde uyanma gibi çeşitli uyku sorunları yaşamaktadır. Farmakolojik yöntemler uyku sorunu yaşayan hastaların tedavisinde en çok bilinen ve en sık başvurulan yöntemlerdendir. Ancak uyku sorununa yönelik alınan ilaçların uzun süre kullanımı sonucunda ciddi yan etki geliştirme potansiyelinin olduğu bildirilmektedir. Bu nedenle özellikle son yıllarda uyku sorunu yaşayan bireylerde uyku kalitesini arttırmak için nonfarmakolojik yöntemlerin kullanımı giderek artmaktadır. Bu yöntemlerin hemşirelik girişimlerinin bir parçası olarak kullanılması ve hasta bakımına dahil edilmesiyle birlikte profesyonelleşme sürecinin hızlanacağı düşünülmektedir. Bu derlemenin amacı; uyku sorunlarını önlemede önemli bir role sahip olan hemşirelere kalp yetersizliği hastalarında uyku sorunlarını erken dönemde tanılama, uyku sorunlarına neden olan faktörleri belirleme ve çözüme yönelik nonfarmakolojik tedavi yöntemleri hakkında bilgi vermektir.
\end{abstract}

Anahtar sözcükler: Kalp yetersizliği; kanıta dayalı uygulamalar; nonfarmakolojik yöntemler; uyku sorunları.

\section{Sleep Problems In Patients With Heart Failure and Non-Pharmacological Treatment}

\begin{abstract}
Sleep, which is a basic and essential requirement, is the most important factor affecting the quality of life and well-being in patients with heart failure. Symptoms such as respiratory disorder, cough, fatigue, nocturia and depression seen in heart failure cause disorder in sleep quality, and sleep quality disorder increases the symptoms of the disease while decreasing the quality of life. Patients with heart failure experience various sleep problems such as difficulty in falling asleep and maintaining sleep, frequently waking during the night, daytime somnolence, and waking up very early in the morning. Pharmacological methods are among the most common and frequently used methods in the treatment of patients with sleep problems. However, it is reported that there is a potential for developing serious side effects as a result of prolonged use of drugs that are taken to treat sleep problems. Therefore, especially in recent years, the use of non-pharmacological methods in individuals with sleep problems has been gradually increasing. It is thought that with the use of these methods as part of nursing interventions and their inclusion in patient care, the professionalization process will accelerate. The purpose of this
\end{abstract}

\footnotetext{
İletişim (Correspondence): Abdullah Avcı, Mersin Üniversitesi Hastanesi, Kardiyoloji Kliniği, Mersin
}

Telefon (Phone): +90 5066645728 E-Posta (E-mail): abdullahavci@mersin.edu.tr

Başvuru Tarihi (Submitted Date): 10.06.2020 Kabul Tarihi (Accepted Date): 20.08.2020

oCopyright 2020 by Turkish Society of Cardiology - Available online at www.anatoljcardiol.com

OPEN ACCESS This work is licensed under a Creative Commons Attribution-NonCommercial 4.0 International License. 
compilation is to inform nurses, who have an important role in preventing sleep problems, about the early diagnosis of sleep problems in the patients with heart failure, detecting the factors that cause sleep problems and the non-pharmacological treatment methods for solution.

Keywords: Evidence-based practices; heart failure; non-pharmacological methods; sleep problems.

Cite this article as: Avcı A, Gün M. Sleep Problems In Patients With Heart Failure and Non-Pharmacological Treatment. Turk J Cardiovasc Nurs 2020;11(25):90-99.

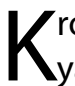
ronik ve ilerleyici bir hastalık olan kalp yetersizliği (KY), yaşlı popülasyona sahip toplumlarda oldukça sık görülen, düşük yaşam kalitesiyle karakterize, mortalite ve morbidite açısından yüksek oranlara sahip, hızla büyüyen önemli bir halk sağlığı sorunudur. ${ }^{[1-3]}$ Dünyada 40 milyona yakın ülkemizde ise üç milyona yakın KY tanısı olan birey yaşamaktadır. $^{[2,4]}$

Bireyin vazgeçilmez günlük yaşam aktivitelerinden biri olan uyku, fizyolojik ve psikolojik sağlığı birçok açıdan etkileyen bir kavram olup sağlığın önemli bir değişkeni olarak görülmektedir. İnsan yaşamının yaklaşık üçte birini kapsayan uyku, yeme-içme, nefes alma, boşaltım kadar önemli olan fizyolojik ve temel gereksinimlerden biridir. ${ }^{[5,6]} \mathrm{KY}$ olan bireylerin hastalığın doğası gereği yaşadıkları nefes darlığı, halsizlik ve yorgunluk gibi semptomlar, tedavide kullanılan ilaçlar ve sınırlı fonksiyonel kapasite nedeniyle bireyin günlük yaşam aktivitelerinin temel bileşeni olan uyku kalitesi azalmakta ve uyku sorunları meydana gelmektedir. ${ }^{[7-11]}$ Literatür incelendiğinde KY hastalarında bildirilen subjektif uyku sorunları prevalansının \%60-95 arasında olduğu görülmektedir. ${ }^{[7-11,12]}$ Ayrıca KY olan bireylerde uykuyu başlatma ve sürdürmede zorluk, insomnia, uyku apne sendromu, aşırı gündüz uykusu gibi uyku bozukluklarına da sık rastlandığı belirtilmektedir. ${ }^{[8,11,13-16]} \mathrm{KY}$ olan ve olmayan hastaların uyku özelliklerinin karşılaştırıldığı bir çalışmada, KY hastalarının \%36.2'si sabahın erken saatinde uyanırken, KY olmayan hastaların \%11.1'inin erken uyandığı tespit edilmiştir. Yine aynı çalışmada KY olan hastaların daha düşük uyku kalitesine sahip oldukları ve daha çok gündüz uykululuk hali yaşadıkları belirlenmiştir. ${ }^{[17]}$ Başka bir çalışmada KY hastalarının \%31.3'ünün kronik uykusuzluk belirtileri gösterdiği bildirilmiş, paroksismal noktürnal dispne ve New York Kalp Birliği (NYHA) sınıflama durumu uykusuzluk ile ilişkilendirilmiştir. ${ }^{[18]}$ KY hastalarının bir yıl boyunca uyku problemlerinin seyrini ve yeniden hastaneye yatış arasındaki ilişkiyi belirlemek amacıyla yapılan bir çalışmada ise KY hastalarının hastaneden taburcu olduktan bir yıl sonra üçte birinin uyku sorunlarının devam ettiği belirlenmiştir. Ayrıca uyku sorunları devam eden hastaların yeniden hastaneye yatış riskinin iki kat fazla olduğu tespit edilmiştir. ${ }^{[9]}$ Bütün bu olumsuz sonuçlar KY olan hastaların yaşadıkları uyku sorunlarının daha iyi anlaşılması gerektiğini vurgulamaktadır.

Uyku organizmanın dinlenmesini ve zihnin yenilenmesini sağlamasının yanı sıra bireyin iyilik durumunu da etkileyen vazgeçilmez bir gereksinimdir. Bu özelliği nedeniyle KY hastalarında öz bakım gücünü ve yaşam kalitesini etkileyen önemli günlük aktiviteler arasında yer almaktadır. ${ }^{[14]}$ Literatür bilgisine göre KY hastalarında uyku sorunlarının hastalık ve tedaviyle ilişkili olduğu, bunların dışında ise ileri yaş, cinsiyet gibi demografik özellikler, komorbid durumlar, hareketsiz yaşam ve emosyonel durum gibi faktörlerin uyku bozukluklarına katkıda bulunduğu bildirilmektedir. ${ }^{[8-11]}$ Diğer taraftan KY hastalarında görülen uyku düzenindeki değişiklikler hastalığın prognozunu olumsuz yönde etkileyebilmektedir. ${ }^{[20]}$

Kalp yetersizliği olan bireylerin uyku sorunlarını tanımlamada, uykuyu olumsuz yönde etkileyen faktörleri belirlemede ve uyku kalitesini arttırmada anahtar rol oynayan hemşirelerin bakım verdikleri hastalara bütüncül bir yaklaşım sergileyebilmeleri için hastanın var olan problemleriyle birlikte yaşadıkları uyku sorunlarını da dikkate almaları gerekmektedir. Farmakolojik yöntemler uyku sorunu yaşayan hastaların tedavisinde en çok bilinen ve en sık başvurulan yöntemlerdendir. Ancak uyku sorununa yönelik kullanılan ilaçların uzun süre kullanımı sonucunda ciddi yan etki geliştirme potansiyelinin olduğu da bilinmektedir. ${ }^{[21]}$ Bu nedenle özellikle son yıllarda uyku sorunu yaşayan bireylerde uyku kalitesini arttırmaya yönelik olarak nonfarmakolojik yöntemlerden de yararlanılmaktadır. Literatürde masaj, aromaterapi, müzik gibi nonfarmakolojik yöntemlerin uyku sorunu yaşayan bireylerde tıbbi tedavinin yanında yardımCı olarak uygulanabildiği ve uyku sorunlarını azaltmada etkili olduğu bildirilmektedir. ${ }^{[22-28]}$ Hemşireler uygulaması kolay ve etkin olan, bireye ekonomik yük getirmeyen bu yöntemlerin birçoğundan kendi kararları doğrultusunda yararlanarak aktif olarak uyku kalitesinin arttırılmasına katkıda bulunabilmektedir. Bu derlemenin amacı; hemşirelerin KY hastalarında uyku sorunlarını erken dönemde tanılama, uyku sorunlarına neden olan faktörleri belirleme, çözüme yönelik nonfarmakolojik tedavi yöntemleri hakkında bilgilendirmektir.

\section{Uykunun Fizyolojisi ve Patofizyolojisi}

Uyku, organizmanın çevreyle olan iletişiminin geçici, kısmi ve periyodik olarak geri döndürülebilir biçimde kesilmesi sürecidir. Bu süre zarfında bedenin fiziksel ve ruhsal açıdan dinlenmesini, dokuların onarılmasını ve zihnin güçlenmesini sağlayarak bireyi yeni bir güne hazırlamaktadır. ${ }^{[5,6]}$ 
Uyku ve uyanıklık temel olarak beyin sapında bulunan retiküler aktivasyon sistemi ve bulbar senkronize edici sistem tarafından düzenlenmektedir. Uyku ve uyanıklık, beyin sapında bulunan bu bölümlerdeki özel merkezlerin bir sıra ve düzen içinde etkin hale gelmesi sayesinde başlayıp sürdürülen aktif bir işlevdir. ${ }^{[5,29]}$ Uyku monoton ve pasif bir süreç değil, kendi içinde belirli bir düzeni olan etkin ve değişken bir süreçtir. Uykunun, çok hafif uykudan çok derin uykuya kadar uzanan farklı düzeyleri vardır. Kişi her gece, birbirini izleyen iki farklı uyku tipinden oluşan aşamalar yaşar. Bunlardan ilki hızlı göz hareketlerinin olmadığı yavaş dalga uykusu NREM (Non-Rapid Eye Movement/yavaş göz hareketleri), ikincisi ise hızlı göz hareketlerinin olduğu REM (Rapid Eye Movement) uyku bölümleridir. ${ }^{[5,6,30]}$

\section{Kalp Yetersizliğinde Uyku Sorunlarına Neden Olan Faktörler}

Kalp yetersizliği olan hastalarda hastalığa bağlı olarak gelişen semptomlar, yaşanan semptomların fiziksel ve ruhsal etkileri, tedavi amacıyla kullanılan ilaçlar vb. pek çok neden ile ilişkili olarak uyku problemleri yaşanabilmektedir. $[7-9,11,31,32]$

Kalp yetersizliği olan hastaların uyku düzenindeki ve/veya kalitesindeki bozukluklara neden olan hastalığın semptomları dışında da çeşitli faktörler bulunmaktadır. Bunlardan bir kısmı şu şekildedir:

İlerleyen yaş: Yaşın ilerlemesi, pek çok fizyolojik ve zihinsel değişikliğe uğrayan bir yaşam evresidir. Uyku bozuklukları yaşlı popülasyonunda önemli bir sağlık sorunu oluşturmakta ve yaşlı yetişkinler uykuyu başlatma ve sürdürme dahil birtakım uyku problemleri yaşayabilmektedir. ${ }^{[33]}$ Ayrıca yaşlanma süreci ile birlikte kalp yetersizliği gibi kronik hastalıkların yaygın olarak görüldüğü, normal uyku düzeninde bazı değişikliklerin meydana geldiği, uyku kalitesinde memnuniyetin azaldığı ve uykusuzluk yakınmalarının arttığı bilinmektedir. ${ }^{[8,10]}$

Solunum örüntüsünde değişme: KY olan hastalarda kardiyak out-put'ta azalmaya bağlı olarak geriye doğru akciğerlerde sıvı birikmekte bu da çeşitli derecelerde nefes darlığının gelişmesine neden olmaktadır. KY hastalarında sık aralıklarla yaşanan nefes darlığı hastaların uykuya dalma ve uykuyu sürdürebilmelerini zorlaştırmakta ve uyku bölünmesine neden olarak uyku düzenini bozabilmektedir. [8,11] Ayrıca KY hastalarında üst solunum yollarında gelişen venöz konjesyona bağlı havayolu lümen daralması sonucu Obstruktif Uyku Apnesi Sendromu gelişmekte ve bu durum hem gündüz uykululuk halini hem de gece uykusuzluk probleminin gelişmesine katkıda bulunmaktadır. ${ }^{[3,35]}$

Fiziksel aktivite toleransında azalma: $\mathrm{KY}^{\prime}$ de kalp debisinin azalması sonucu iskelet kası ve organ perfüzyonunun azalmasına bağlı olarak halsizlik ve yorgunluk gibi semptomlar sık görülebilmektedir. KY tanısı olan hastalar halsizlik ve yorgunluk semptomlarını sık aralıklarla yaşadıkları için gün içinde birkaç kez uyuklama ihtiyacı duyabilmektedir. ${ }^{[13]}$ Bu nedenle de hastalar gece uykusunu başlatma ve sürdürmede sorun yaşayabilmektedir. ${ }^{[36]}$

İlaç Kullanımı: KY sendromunu yönetmek için kullanılan diüretik, beta bloker ve anjiotensin dönüştürücü enzim inhibitörü gibi ilaçlar uyku kalitesini olumsuz etkileyebilmektedir. ${ }^{[7,37]}$ Örneğin diüretik kullanımı sonucunda noktüri gelişerek uyku bölünmesi gerçekleşmekte ve uyku kalitesi azalmaktadır. Beta blokerlerin gece gündüz melatonin üretimindeki azalmalar yoluyla insomnia ve kabus görmeye neden olarak uykuyu olumsuz yönde etkileyebilmektedir. Anjiotensin dönüştürücü enzim inhibitörlerinin öksürüğü şiddetlendirerek uyku düzenini bozabilmektedir. ${ }^{[37]}$

Emosyonel durum: Kalp yetersizliği bulunan bireyler hastalığın doğası gereği nefes darlığı, yorgunluk, ödem, düşük fiziksel aktivite, günlük yaşam aktivitelerini yerine getirmede bağımlılık ve yaşamın sonunu geldiğini düşünmeye bağlı ölüm korkusu yaşamaktadırlar. KY hastalarında görülen bu durumlar anksiyete, stres ve depresyon gelişimi için önemli risk faktörleri olarak kabul edilmektedir. ${ }^{[9,32]}$

\section{Kalp Yetersizliği Hastalarında Uyku Sorunlarının Giderilmesine Yönelik Nonfarmakolojik Yöntemler}

Kalp yetersizliği hastalarında uyku sorunlarını azaltmak için tıbbi tedavinin yanı sıra nonfarmakolojik yöntemlere de sıklıkla başvurulmaktadır. Farmakolojik yöntemler uyku sorunu yaşayan hastaların tedavisinde en çok bilinen ve en sık başvurulan yöntemlerdendir. Ancak uyku sorununa yönelik kullanılan ilaçların uzun süre kullanımı sonucunda ciddi yan etki geliştirme potansiyelinin olduğu da bilinmektedir. ${ }^{[21]}$ Bu nedenle özellikle son yıllarda uyku sorunu yaşayan bireylerde uyku kalitesini arttırmaya yönelik olarak nonfarmakolojik yöntemlerden de yararlanılmaktadır. Literatürde KY hastalarının uyku kalitesini iyileştirme amacıyla uyku hijyeni eğitimi, çevre düzenlemesi, tedavi planın ayarlanması ve aktivite planlaması gibi genel girişimlerin yanı sıra aromaterapi, masaj, müzik, akupresör gibi girişimlerin de uygulandığı görülmektedir. Uygulaması kolay ve etkin olan, bireye ekonomik yük getirmeyen nonfarmakolojik yöntemlerin uyku sorunlarını azaltmada etkili olabileceğini gösteren kanıtlar bulunmaktadır. ${ }^{[22-28,38-46]} \mathrm{KY}$ olan hastalarda nonfarmakolojik yöntemlerin uyku kalitesine etkisini inceleyen çalışmaların özellikleri tablo 1'de verilmiştir.

Uyku Hijyeni Eğitimi: Uyku sorunu olan KY hastalarının bakım ve tedavisini yürüten hemşirelerin uyku bozukluk- 


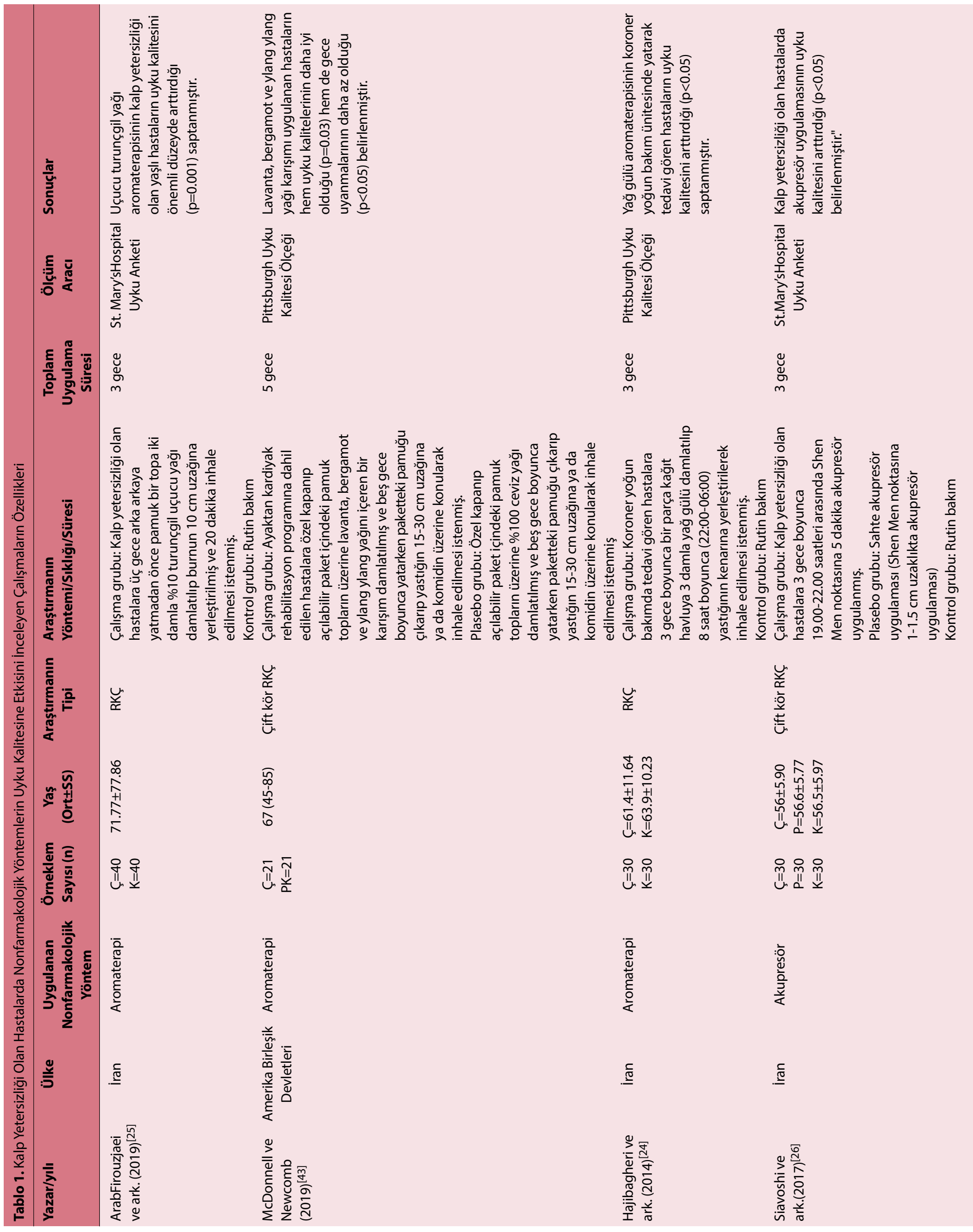




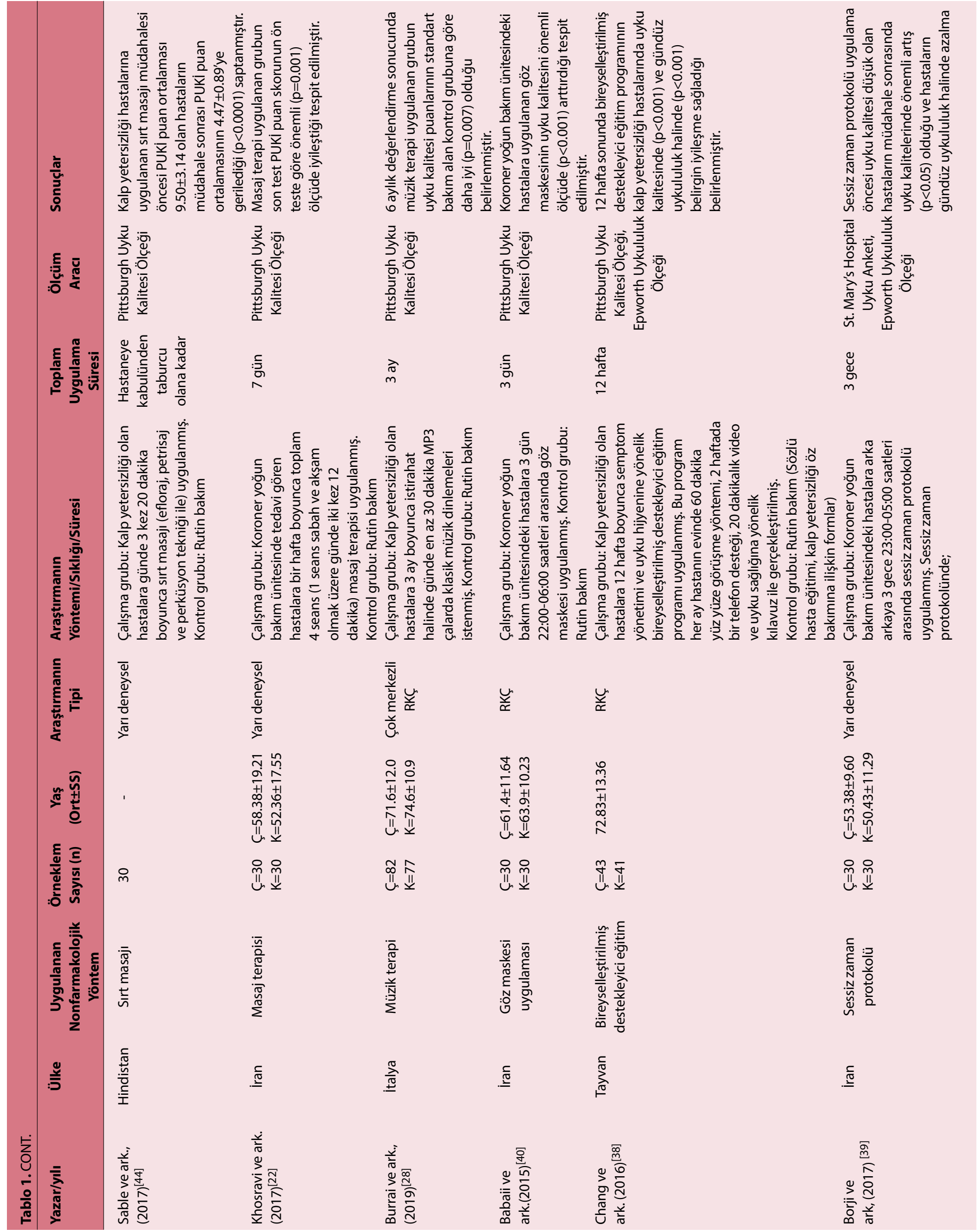




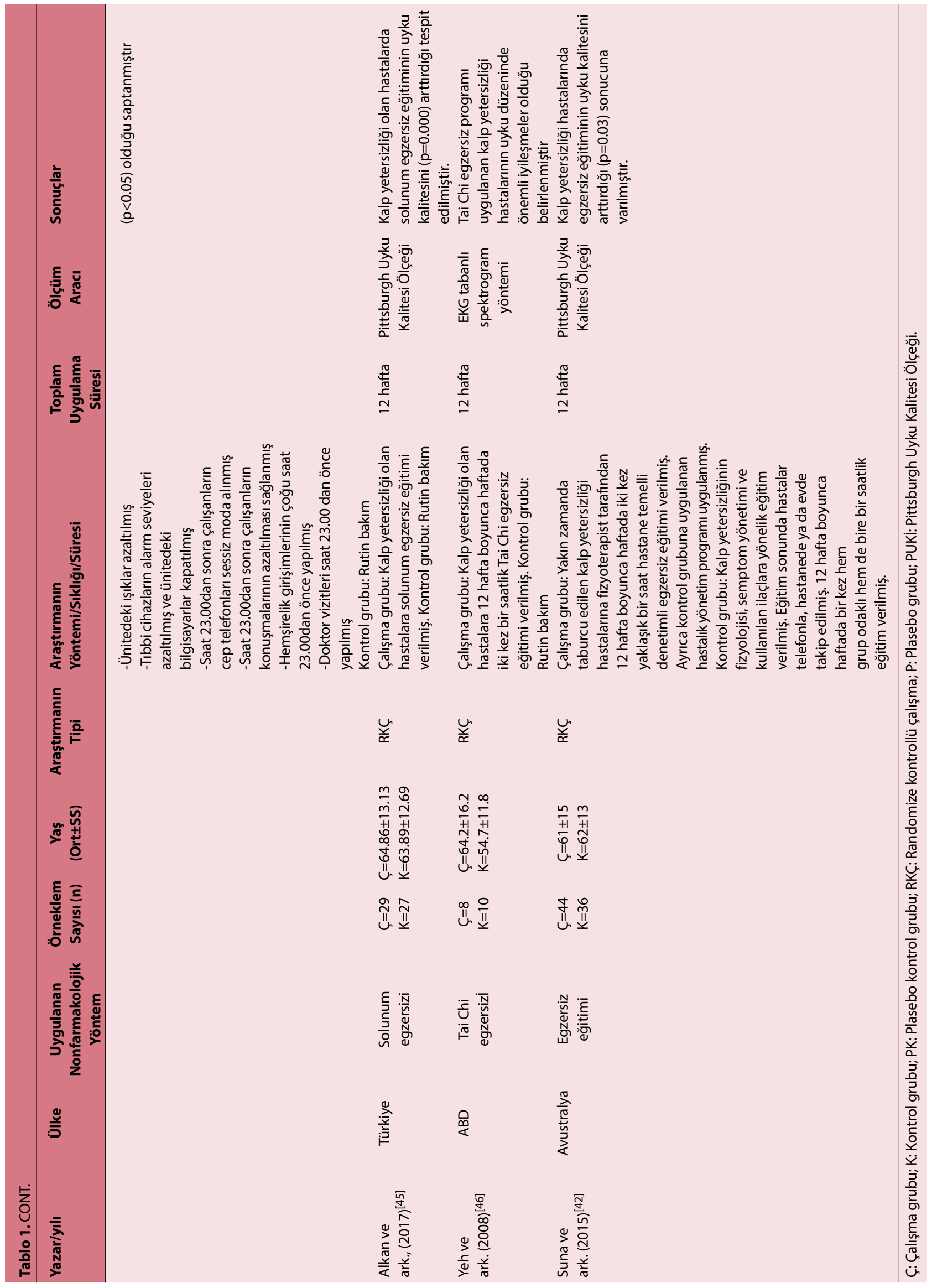


ları belirtileri yönünden gözlemleme, erken dönemde saptama, etkileyen faktörleri belirleme ve hastalara etkili baş etme yöntemlerini öğretmeye yönelik önemli rol ve sorumlulukları bulunmaktadır. Hemşirelerden eğitici rollerini kullanarak hastaların uyku kalitesinin artmasına yardımcı olan uyku hijyeni eğitimi ile hastaların uykularını düzenlemeleri ve dinlenmelerini sağlayarak hastalara destek vermeleri beklenmektedir. Yapılan randomize kontrollü bir çalışmada KY hastalarına hemşireler tarafından 12 hafta boyunca yüz yüze eğitim oturumları, ev ziyaretleri ve telefon görüşmeleri gerçekleştirilerek bireyselleştirilmiş destekleyici eğitim programı sunulmuştur. 12 hafta sonunda hastaların, uyku kalitesinde ve gündüz uykululuk halinde belirgin iyileşme olduğu saptanmıştır. [38]

Çevrenin düzenlenmesi: Gürültü ve ışık gibi faktörleri ortadan kaldırarak hasta birey için dinlendirici bir ortam hazırlamak ve çevre düzenini sağlamak, uyku ve diğer temel fizyolojik gereksinimlerinin yerine getirilmesine yardımcı olmak hemşirelerin temel görevlerinden biridir. Javadi ve arkadaşlarının (2015) hastanede yatarak tedavi gören KY hastaları ile yaptıkları çalışmada, hastaların yarısının gürültü, \%27'sinin ise ışık nedeniyle uykularının bölündüğünü bildirmiştir. ${ }^{[10]}$ Örneklem grubunun \%15'ini KY hastalarının oluşturduğu koroner yoğun bakım ünitesinde yatarak tedavi gören kalp hastaları ile yapılan bir çalışmada ise, sessiz zaman protokolünün uyku kalitesi üzerindeki etkileri değerlendirilmiştir. Çalışma sonunda sessiz zaman protokolü uygulama öncesi uyku kalitesi düşük olan hastaların müdahale sonrasında uyku kalitelerinde önemli artış olduğu ve hastaların uykululuk halinde azalma olduğu belirlenmiştir. [39]

Uygun pozisyon verilmesi: Uyku sorunu yaşayan hastaların normal uyku düzeni ve alışkanlıkları değerlendirilmeli, uyku ritüellerinin sorgulanması gerekmektedir. Hastanın rahat uyuyabilmesi için yastık sayısı arttııımalı, hastanın rahat uyku pozisyonunu almasına yardmcı olunmalı ve göz maskesi gibi uykuyu kolaylaştıracak yaklaşımlar kullanılmaIıdır. Koroner yoğun bakım ünitesindeki hastalara uygulanan göz maskesinin uyku kalitesine etkisinin incelendiği bir çalışmada hastalara 3 gün 22.00-06.00 saatleri arasında göz maskesi uygulanmıştır. Müdahale grubunun \%23'ünü KY hastalarının oluşturduğu çalışma sonucunda göz maskesinin uyku kalitesini önemli ölçüde arttırdığı tespit edilmiştir. [40] Uyku apnesi olan KY hastalarında vücut pozisyonunun uyku apnesi üzerindeki etkilerinin incelendiği çalışmada lateral pozisyonda uyumanın uykuda solunum olaylarının sıklığını belirgin şekilde azalttığı saptamıştır. ${ }^{[41]}$

Tedavi planının ayarlanması: Sık hemşirelik girişimleri hastaların uykularının bölünmesine neden olarak uyku problemi yaşamalarına sebep olmaktadır. Bu nedenle normal uyku saatleri arasında gereksiz uygulamalar en aza indirgenmeli, gece yapılacak işlemler hastanın uykusunu kesintiye uğratmayacak şekilde düzenlenmeli ve hastaların uyku önceliğinin sağlanması için hemşirelik uygulamaları organize edilmelidir. Yapılan bir çalışmada KY hastalarının \%29'unun vital bulgu takibi, \%31'inin ise gece yapılan tanı testlerine yönelik girişimler nedeniyle uyku sorunu yaşadıkları tespit edilmiştir. ${ }^{[10]}$ KY hastalarında gece uyku bölünmesini önlemek için diüretik ilaçların sabah ve öğle saatlerinde verilmesi büyük önem taşımaktadır. Diüretiklerin uygunsuz kullanımı gece sık idrara çıkmaya neden olmakta ve bu durum hastaların uykularının bölünmesine sebep olmaktadır. Örneklem grubunu KY hastalarının oluşturduğu çalışmada diüretik kullanan hastaların uyku kalitelerinin daha düşük olduğu bildirilmiştir. ${ }^{[8]}$

Aktivite planlaması ve egzersiz: Kalp yetersizliği olan hastalar gece kesintisiz ve kaliteli uyuyamaması sonucu gün içinde birkaç kez uyuklama ihtiyacı duymaktadır. Bunun sonucunda hastalar gece uykusunu başlatma ve sürdürme de sorun yaşamaktadır. Riegel ve ark. ${ }^{[13]}$ (2012) KY olan hastalarda gündüz uykululuk halinin prevalansını ve yorgunluk ile ilişkisini araştırdıkları çalışmasında hastaların \%23.6'sında gündüz uykululuk hali olduğu belirlenmiştir. Bu nedenle KY hastalarının gündüz saatlerinde uyumaktan kaçınılması sağlanmalıdır. Hemşireler hastaların gündüz uyumasını engelleyerek gün içinde aktivite planlarını arttırmalıdır.

Kalp yetersizliği hastalarında görülen nefes darlığı, halsizlik ve çabuk yorulma nedeniyle egzersiz intoleransı ve dolayısıyla fonksiyonel kapasite bozulmuştur. Yapılan bir çalışmada KY olan hastaların fonksiyonel kapasitelerinin yetersiz, uyku kalitesinin ise düşük olduğu bildirilmiştir. ${ }^{[36]} \mathrm{KY}$ olan hastalarda egzersizin uyku kalitesine etkisinin değerlendirildiği randomize kontrollü çalışmada, 12 hafta boyunca haftada 2 kez iki saatlik egzersiz eğitimi verilen müdahale grubu ile standart bakım alan kontrol grubu karşılaştırılmıştır. 12 haftanın sonunda egzersiz eğitimi alan grubun uyku kalitesinin daha iyi olduğu saptanmıştır. ${ }^{[42]} \mathrm{KY}$ hastalarında fonksiyonel kapasitenin düzeltilmesi uyku kalitesini de arttıracağından hastalara gün içinde 30 dakika orta yoğunlukta egzersiz yapılması önerilebilir.

Aromaterapi: Bitkisel kökenli esansiyel yağları destekleyici amaçla kullanılan bir tedavi yöntemi olan aromaterapinin rahatlatıcı ve sedatif etkisinin olduğu, düz kasları gevşettiği bu özellikleri nedeni ile uyku kalitesini olumlu yönde etkilediği bilinmektedir. Yapılan bir çalışmada 3 gece 8 saat süre ile uygulanan yağ gülü aromaterapisinin uyku gecikmesi ve 
uyku bozukluklarını önemli ölçüde azalttığı, uyku süresini ve uyku kalitesini arttırdığı saptanmıştır. ${ }^{[24]}$ Başka bir çalışmada ise KY olan yaşlı hastalarda turunç aromaterapisinin uyku kalitesi üzerine etkisi incelenmiş; arka arkaya 3 gece boyunca yirmi dakika uygulanan turunç aromaterapisinin uyku kalitesini arttırdığı belirlenmiştir. ${ }^{[25]}$ Kardiyak rehabilitasyon programına dahil edilen hastalarla yapılan bir çalışmada ise müdahale grubuna 5 gece lavanta, bergamot ve ylang ylang yağını içeren bir karışım ile aromaterapi uygulanmış, plasebo grubuna ise yine 5 gece sahte aromaterapi uygulanmıştır. Çalışma sonunda müdahale grubundaki hastaların uyku kalitesinin plasebo grubundan daha iyi olduğu tespit edilmiştir. ${ }^{[43]}$

Akupresör: Vücudun kendi kendine iyileştirici yeteneklerini harekete geçiren önemli şifa noktalarına basmak için parmak kullanılarak yapılan bir iyileştirme sanatıdır. Terapötik masajın bir alt tipi olarak sınıflandırılan akupresörün ana felsefesi evrende var olan enerji akışları arasında birlik, denge ve uyuma dayanmaktadır. KY olan 90 hastanın dahil edildiği ve çift kör randomize plasebo kontrollü olarak tasarlanan bir çalışmada akupresör uygulamasının uyku kalitesini arttırdığı belirlenmiştir. ${ }^{[26]}$

Masaj: Kaslardaki gerginliği azaltarak rahatlama sağlayan ve anksiyeteyi azaltan masaj, uykuya geçişi de kolaylaştırmakta, uyku kalitesini ve konforu arttırmaktadır. Uyku öncesi sırt masajı rahatlatıcı olabilmekte ve hasta ile hemşire arasındaki bütünlüğü sağlayarak bireyin kaygısını ve rahatsızlığını dile getirmesini ve soru sormasını sağlayabilmektedir. KY hastalarına uygulanan sırt masajının uyku kalitesine etkisinin değerlendirildiği bir çalışmada, hastalara günde 3 kez 20 dk sırt masajı uygulanmıştır. Müdahale sonrası hastaların uyku kalitesinde belirgin artış görüldüğü saptanmıştır. Ayrıca müdahale öncesi hastaların \%37'sinin 8 saatten fazla uyuduğu, sırt masajı sonrası bu oranın \%73'e yükseldiği belirlenmiştir. ${ }^{[44]}$ Khosravi ve ark. (2017) koroner yoğun bakım ünitesinde tedavi gören hastalarda masaj terapisinin uyku kalitesi üzerine etkisini standart bakım alan kontrol grubu ile karşılaştırılarak değerlendirilmiştir. 1 hafta boyunca toplam 4 seans masaj terapisi uygulanan girişim grubunda kontrol grubuna göre uyku kalitesinin arttığı saptanmıştır. ${ }^{[22]}$

Solunum ve öksürük egzersizi: Kalp yetersizliğinin en sık ve en erken belirtisi olan nefes darlığı hastaların uykuyu sürdürebilmelerini zorlaştırmakta ve uyku sorunu yaşanmasına yol açmaktadır. Gau ve ark. KY olan yaşlı ve genç hastaların uyku kalitesini etkileyen faktörleri belirledikleri çalışmasında, hem genç hem de yaşlı hastalarda düşük uyku kalitesinin en önemli belirleyicisinin dispne olduğu saptanmıştır. ${ }^{[12]}$ Solunum ve öksürük egzersizleri hastalarda gaz değişiminin düzenlemesine olanak sağlayarak akciğer kapasitesini arttırmaktadır. Ayrıca alveollerin kollabe olmasını önleyerek solunum fonksiyonunu da kolaylaştırmaktadır. Bunun sonucunda hastalar solunumunu nasıl kontrol edeceğini öğrenmekte, nefes darlığı azalmakta ve gevşeme meydana gelmektedir. KY olan hastalara verilen solunum egzersizi eğitiminin dispne düzeyi ve uyku kalitesine etkisinin incelendiği çalışma sonucuna göre solunum egzersizi eğitiminin dispne seviyesini azalttığı, uyku kalitesini ise arttırdığı tespit edilmiştir. ${ }^{[45]}$

Gevşeme egzersizleri: Bu egzersiz istemli olarak vücuttaki büyük kas gruplarının gerilip gevşetilmesini içermektedir. Burada amaç gevşemeyle birlikte bireyin vücudundaki gerginlik ile gevşeme arasındaki farkı hissetmesini sağlamaktır. Kamal ve ark. (2019) yapmış oldukları sistematik derlemede KY hastalarında uyku hijyeni ve benson gevşeme tekniğinin uyku kalitesini arttırdığı sonucuna varılmıştır. ${ }^{[27]}$ Kwekkeboom ve ark. (2016) yaptığı sistematik derlemede ise KY hastalarında bilişsel davranışçı stratejilerin uyku bozukluklarını azalttığı saptanmıştır. ${ }^{[24]} \mathrm{KY}$ olan ve sol ventrikül ejeksiyon fraksiyonu \%40'ın altında olan hastalarla yapılan randomize kontrollü çalışmada müdahale grubuna 12 hafta boyunca haftada 2 gün Tai Chi egzersiz programı uygulanmış, kontrol grubuna ise standart bakım verilmiştir. 12 hafta sonunda Tai Chi egzersiz programı uygulanan hastaların uyku düzeninde önemli iyileşmeler olduğu belirlenmiştir. ${ }^{[46]}$

Müzik terapi: Müzik terapi, nöroendokrin ve sempatik sinir sistemi üzerine etki ederek, kalp atım hızının, solum sayısının, kan basıncının ve anksiyete düzeyinin azalmasını sağlayarak bireylerin uyku kalitesini arttırmaktadır. KY hastalarında ev ortamında klasik müzik dinlemenin etkisinin incelendiği randomize kontrollü bir çalışmada müdahale grubuna 3 ay boyunca günde en az 30 dakika klasik müzik dinlettirilirken kontrol grubuna standart bakım verilmiştir. Her iki grupta 6 aylık değerlendirme sonucunda müdahale grubunun uyku kalitesi puanlarının kontrol grubuna göre daha iyi olduğu belirlenmiştir. ${ }^{[28]}$

\section{Sonuç ve Öneriler}

Uyku sorunu olan KY hastalarının bakım ve tedavisini yürüten hemşirelerin uyku bozuklukları belirtileri yönünden gözlemleme, erken dönemde saptama, etkileyen faktörleri belirleme ve hastalara etkili baş etme yöntemlerini öğretmeye yönelik önemli rol ve sorumlulukları bulunmaktadır. KY hastalarına bakım veren hemşirelerden uyku sorunlarına yönelik standart uygulamaların yanında nonfarmakolojik yöntemleri de uyku sorunu yaşayan bireyin bakımına 
dahil etmeleri ve hemşirelik girişimlerinin bir parçası olarak kullanılması önerilmektedir. Ayrıca hemşirelerden nonfarmakolojik yöntemlerden kanıta dayalı olanların tercih edilmesi gerektiği konusunda hastalara rehberlik yapmaları ve bu yöntemleri doğru ve etkin kullanmaları konusunda bilgilendirmeleri beklenmektedir.

Hakem Değerlendirmesi: Dış bağımsız.

Çıkar Çatışması: Yazarlar arasında herhangi bir çıkar çatışması bulunmamaktadır.

Yazarlık Katkıları: Konsept: M.G., A.A.; Dizayn: M.G., A.A.; Veri Toplama veya İşleme: A.A.; Analiz veya Yorumlama: A.A.; Literatür Arama: A.A.; Yazan: M.G., A.A.

\section{Kaynaklar}

1. Roger VL. Epidemiology of heart failure. Circ Res 2013;113(6):646-59. [CrossRef]

2. Ziaeian B, Fonarow GC. Epidemiology and aetiology of heart failure. Nat Rev Cardiol 2016;13(6):368-78. [CrossRef]

3. Ponikowski P, Voors AA, Anker SD, Bueno H, Cleland JG, Coats AJ, et al. 2016 ESC Guidelines for the diagnosis and treatment of acute and chronic heart failure: The Task Force for the diagnosis and treatment of acute and chronic heart failure of the European Society of Cardiology (ESC). Developed with the special contribution of the Heart Failure Association (HFA) of the ESC. Eur J Heart Fail 2016;18(8):891-975. [CrossRef]

4. Değertekin M, Erol C, Ergene O, Tokgözoğlu L, Aksoy M, Erol MK, et al. Türkiye'deki kalp yetersizliği prevalansı ve öngördürücüleri: HAPPY çalışması [Heart failure prevalence and predictors in Turkey: HAPPY study]. [Article in Turkish]. Turk Kardiyol Dern Ars 2012;40(4):298-308. [CrossRef]

5. Şahin $L$, Aşçıŏlu M. Sleep and Regulation of Sleep. Sağlık Bilimleri Dergisi 2013;22(1):93-8.

6. Pıçak R, İsmailoğulları S, Mazıcıoğlu MM, Üstünbaş HB, Aksu M. Birinci Basamakta Uyku Bozukluklarına Yaklaşım ve Öneriler. Turkish Journal Of Family Medicine And Primary Care 2010;4:12-22.

7. Wang TJ, Lee SC, Tsay SL, Tung HH. Factors influencing heart failure patients' sleep quality. J Adv Nurs 2010;66(8):1730-40.

8. Moradi M, Mehrdad N, Nikpour S, Haghani H, Aalaa M, Sanjari $M$, et al. Sleep quality and associated factors among patients with chronic heart failure in Iran. Med J Islam Repub Iran 2014;28:149.

9. Nasir U, Shahid H, Shabbir MO. Sleep quality and depression in hospitalized congestive heart failure patients. J Pak Med Assoc 2015;65(3):264-9.

10. Javadi N, Darvishpour A, Mehrdad N, Lakeh NM. Survey of Sleep Status and its Related Factors among Hospitalized Patients with Heart Failure. J Tehran Heart Cent 2015;10(1):9-17.

11. dos Santos MA, Guedes Ede S, Barbosa RL, da Cruz Dde A. Sleeping difficulties reported by patients with heart failure. Rev Lat Am Enfermagem 2012;20(4):644-50. [CrossRef]
12. Gau FY, Chen XP, Wu HY, Lin ML, Chao YF. Sleep-related predictors of quality of life in the elderly versus younger heart failure patients: a questionnaire survey. Int J Nurs Stud 2011;48(4):419-28. [CrossRef]

13. Riegel B, Ratcliffe SJ, Sayers SL, Potashnik S, Buck HG, Jurkovitz $\mathrm{C}$, et al. Determinants of excessive daytime sleepiness and fatigue in adults with heart failure. Clin Nurs Res 2012;21(3):27193. [CrossRef]

14. Azevedo IG,Vieira EM, Neto NR, Nogueria ID, Melo FE, Nogueira PA. Correlation between sleep and quality of life in patients with heart failure. Fisioter Pesq 2015;22(2):148-54.

15. Chimluang J, Aungsuroch Y, Jitpanya C. Descriptors of Insomnia among Patients with Heart Failure. J Med Assoc Thai 2017; 100(4):403-9.

16. Javaheri S. Sleep disorders in systolic heart failure: a prospective study of 100 male patients. The final report. Int J Cardiol 2006;106(1):21-8. [CrossRef]

17. Redeker NS, Stein S. Characteristics of sleep in patients with stable heart failure versus a comparison group. Heart Lung 2006;35(4):252-61. [CrossRef]

18. Príncipe-Rodríguez K, Strohl KP, Hadziefendic S, Piña IL. Sleep symptoms and clinical markers of illness in patients with heart failure. Sleep Breath 2005;9(3):127-33. [CrossRef]

19. Johansson P, Broström A, Sanderman R, Jaarsma T. The Course of Sleep Problems in Patients With Heart Failure and Associations to Rehospitalizations. J Cardiovasc Nurs 2015;30(5):40310. [CrossRef]

20. Kanno Y, Yoshihisa A, Watanabe S, Takiguchi M, Yokokawa T, Sato $A$, et al. Prognostic Significance of Insomnia in Heart Failure. Circ J 2016;80(7):1571-7. [CrossRef]

21. Sateia MJ, Buysse DJ, Krystal AD, Neubauer DN, Heald JL. Clinical Practice Guideline for the Pharmacologic Treatment of Chronic Insomnia in Adults: An American Academy of Sleep Medicine Clinical Practice Guideline. J Clin Sleep Med 2017;13(2):307-49. [CrossRef]

22. Khosravi A, Bolourchifard F, Ikhani M, Pourhoseingholi MA. The effect of massage therapy on sleep quality in cardiac care unit patients. Biosci Biotech Res Comm 2017;10:645-51.

23. Kwekkeboom KL, Bratzke LC. A Systematic Review of Relaxation, Meditation, and Guided Imagery Strategies for Symptom Management in Heart Failure. J Cardiovasc Nurs 2016;31(5):457-68. [CrossRef]

24. Hajibagheri A, Babaii A, Adib-Hajbaghery M. Effect of Rosa damascene aromatherapy on sleep quality in cardiac patients: a randomized controlled trial. Complement Ther Clin Pract 2014;20(3):159-63. [CrossRef]

25. Arab Firouzjaei Z, Illali ES, Taraghi Z, Mohammadpour RA, Amin K, Habibi E. The Effect of Citrus Aurantium Aroma on Sleep Quality in the Elderly with Heart Failure. JBUMS 2019;21(1):181-7.

26. Siavoshi M, Vahidi SA, Talebi S, Doroudi M, Shahsavan Y, Bordbar $R$. The effect of acupressure on sleep quality in patients with chronic heart failure. JBUMS 2017;1(2):21-7.

27. Kamal M, Herawati T. The effect of sleep hygiene and relaxa- 
tion Benson on improving the quality of sleep among health failure patients: A literature review. IJNHS 2019;2(1):101-7.

28. Burrai F, Sanna GD, Moccia E, Morlando F, Cosentino ER, Bui $V$, et al. Beneficial Effects of Listening to Classical Music in Patients With Heart Failure: A Randomized Controlled Trial. J Card Fail 2020;26(7):541-9. [CrossRef]

29. Porkka-Heiskanen T, Zitting KM, Wigren HK. Sleep, its regulation and possible mechanisms of sleep disturbances. Acta Physiol (Oxf) 2013;208(4):311-28. [CrossRef]

30. Algın Di, Akdağ G, Erdinç OO. Quality sleep and sleep disorders. Osmangazi Journal of Medicine 2016;38(Special Issue 1):29-34. [CrossRef]

31. Zuurbier LA, Luik AI, Leening MJ, Hofman A, Freak-Poli R, Fran$\mathrm{co} \mathrm{OH}$, et al. Associations of heart failure with sleep quality: the Rotterdam Study. J Clin Sleep Med 2015;11(2):117-21.

32. Aria H, Naghizadeh MM. Sleep Quality, Anxiety, and Depression in Patients With Heart Failure. JAMSAT 2017;3(4):213-20.

33. Akkuş Y, Kapucu S. Yaşlı Bireylerde Uyku Sorunları. İç Hastalıkları Dergisi 2008;15(3):131-5.

34. Genç S, Dikmen N. The new Classification of Sleep Disorders (ICSD-3): The Changes in The Classification Of Sleep Related Breathing Disorder with ICSD-3. Mustafa Kemal Üniv Tıp Derg 2017;8(31):23-31.

35. Dursunoğlu D. Kalp Yetersizliği ve Uykuda Solunum Bozuklukları. Turkiye Klinikleri J Cardiol-Special Topics 2018;11(1):5865.

36. Awotidebe TO, Adeyeye VO, Adedoyin RA, Ogunyemi SA, Oke $\mathrm{Kl}$, Ativie RN, et al. Assessment of functional capacity and sleep quality of patients with chronic heart failure. Hong Kong Physiother J 2016;36:17-24. [CrossRef]

37. Jiménez JA, Greenberg BH, Mills PJ. Effects of Heart Failure and its Pharmacological Management on Sleep. Drug Discov Today Dis Models 2011;8(4):161-6. [CrossRef]

38. Chang YL, Chiou AF, Cheng SM, Lin KC. Tailored educational supportive care programme on sleep quality and psychological distress in patients with heart failure: A randomised controlled trial. Int J Nurs Stud 2016;61:219-29. [CrossRef]

39. Borji M, Otaghi M, Salimi E, Sanei P. Investigating the effect of performing the quiet time protocol on the sleep quality of cardiac patients. Biomedical Research 2017;28(16):7076-80.

40. Babaii A, Adib-Hajbaghery M, Hajibagheri A. Effect of Using Eye Mask on Sleep Quality in Cardiac Patients: A Randomized Controlled Trial. Nurs Midwifery Stud 2015;4(4):e28332. [CrossRef]

41. Pinna GD, Robbi E, La Rovere MT, Taurino AE, Bruschi C, Guazzotti $G$, et al. Differential impact of body position on the severity of disordered breathing in heart failure patients with obstructive vs. central sleep apnoea. Eur J Heart Fail 2015;17(12):1302-9. [CrossRef]

42. Suna JM, Mudge A, Stewart I, Marquart L, O'Rourke P, Scott $A$. The effect of a supervised exercise training programme on sleep quality in recently discharged heart failure patients. Eur J Cardiovasc Nurs 2015;14(3):198-205. [CrossRef]

43. McDonnell B, Newcomb P. Trial of Essential Oils to Improve Sleep for Patients in Cardiac Rehabilitation. J Altern Complement Med 2019;25(12):1193-9. [CrossRef]

44. Sable A, Sivabalan T, Shetti AN. Effectiveness of Back Massage on Sleep Pattern among Patients with Congestive Cardiac Failure. Iran J Nurs Midwifery Res 2017;22(5):359-62.

45. Öz HA, Uysal H, Enç N, Yiğit Z. Influence of Breathing Exercise Education Applied on Patients with Heart Failure on Dyspnoea and Quality of Sleep: A Randomized Controlled Study. International Journal of Medical Research \& Health Sciences 2017;6(9):107-13.

46. Yeh GY, Mietus JE, Peng CK, Phillips RS, Davis RB, Wayne PM, et al. Enhancement of sleep stability with Tai Chi exercise in chronic heart failure: preliminary findings using an ECG-based spectrogram method. Sleep Med 2008;9(5):527-36. [CrossRef] 